\title{
TEMPORAL AND LOCATIVE PREPOSITIONS VERSUS ADVERBS: LEXICAL AND GRAMMATICAL OVERLAPPING (CORPUS-BASED STUDY)
}

\author{
Yurii Kovbasko \\ Vasyl Stefanyk Precarpathian National University, Ivano-Frankivsk, Ukraine \\ y.kovbasko@yahoo.com
}

\begin{abstract}
The paper focuses on an essential problem of a "part-of-speech" theory, including temporal and locative prepositions and adverbs overlapping in lexical and grammatical perspective. The study is pursued on a corpus-based approach towards prepositions and adverbs overlapping in present-day English (PDE), giving consideration to the complements applied. The latter are divided into two wide groups, namely Noun Phrase and Alternative Complements. To organise the results the comparative-parametric method of linguistic research developed by Sternina was introduced. A comparison has been made between traditional interpretation of complement use and practical corpus-based results in PDE. It has been ascertained that among 94 lexical units treated as one-word prepositions 49 units show overlapping of prepositions and adverbs; however, 39 units bear locative and temporal semes. The results of the PDE corpus-based research show that conventional interpretation of prepositions as lexical units governing Noun Phrase Complements and Adverbs as units correlating with Alternative Complements is deceptive, as it is based on a synchronic syntactic approach, neglecting diachronic syntax and semantics. The hypothesis proposed describes a necessity to reconsider modern PoS division theory, taking into account diachronic approach and analysis of lexical units at the stages of their genesis in Old English and Middle English periods.
\end{abstract}

Keywords: adverb; preposition; functional-grammatical transposition; complement; lexical and grammatical combinability; corpusbased study.

\section{Introduction}

Any language and its units are characterised by a certain degree of responsiveness to various external and internal factors, which influence them. Therefore, it presupposes their dynamic nature and stipulates the fact that all linguistic phenomena, despite their statistical character, are in constant motion and interact with each other at different levels, indicating the permanent development of language in diachrony. In this context, the most distinguished dynamic changes describe transposition phenomenon "which makes possible the use of words as members of other classes than their "logical" or natural "word class" (Ketel, 1991, p. 316). According to Lekant (2007) "there are no and can be no borders between parts of speech (PoS): they possess not only different, opposite, but also common features and that is why in language exist hybrid or transient words, which have not found their own word class or left their category under the influence of various linguistic factors" (p. 19).

Traditionally, such transitivity and subsequent use of lexical units as representatives of different parts of speech are observed among open word classes; however, it is a hackneyed subject. We make an assumption that in modern linguistics one of the most significant, current and open problems is a functional-grammatical transposition between open and closed word classes, while one of its manifestations is a "prepositionadverb" overlapping. Current topic has been partially disclosed in works by Heaton (1966), Kiefer (2009), Kiss (2009), Urogdi (2009) and others. We hypothesise that a nominal complement, which in conventional grammar is believed to be a compulsory constituent of a prepositional phrase and an obligatory characteristic of a preposition as a separate part of speech as opposed to adverbs, which omit it, is an optional element that helps to specify speakers' intentions and reflections by no means is a dominant peculiarity of a preposition as a word class. Thus, the aim of the paper is to analyse lexical and grammatical overlapping of temporal and locative prepositions and adverbs, which exists in present day English (PDE), by means of employing corpus-based and corpus-driven approaches.

Analysis of semantic and grammatical overlapping among the lexical units, which belong to adverbs and prepositions, can shed some light on a general problem of part of speech division that is still an open question. It will also contribute to solving ambiguity, when one and the same lexical unit is defined as a representative of two or more word classes.

\section{Methods}

To perform the analysis and implement the objectives of the present paper a "corpus-based" approach, which belongs to major the corpus studies, was applied. The research is built on the British National Corpus (BNC), which is a "100 million word collection of samples of written and spoken language from a wide range of sources". 
The primary goal of the corpus-based research was to conduct the analysis of possible correlations within each word group, i.e. adverbs and prepositions in present-day English. It has not been the analysis of a certain author's discourse, text domain, type or category, but a comprehensive research and evaluation of all accessible instances in the language. First of all, our aim was to single out those lexical units, which simultaneously belong to both word classes, i.e. adverbs and prepositions. As prepositions form a closed word class and thus are limited in their number, for instance Essberger (2009) provides the list of 150 prepositions, which is "comprehensive at the time of writing, and represents all the prepositions currently found in a good English dictionary such as the Concise Oxford Dictionary" (p. 6), we used the category of prepositions as a starting point. Thus, 94 lexical units are classified as modern one-word prepositions and namely they formed the bulk for our investigation. Further on, these 94 lexical units were analysed on the basis of the BNC, each unit defined either as a preposition or as an adverb. Next stage comprises research of the units, comparing types of their complements in detail, specifying various forms of them. Such methodology allows drawing generalised conclusions, concerning the problem of overlapping between two lexical-grammatical categories of prepositions and adverbs; conducting subsequent "corpus-driven" research on functional-grammatical transposition in PDE.

\section{Results and Discussion}

Traditional definition of prepositions as words, which indicate relations between other lexical units and are obligatory clustered with NPs, as their complements let us derive an oppositional assumption - if words, indicating relations between other lexical units, do not use NPs, they cannot be classified as prepositions, and are consequently defined as adverbs. Such hypothesis quite well corresponds with distributional analysis theory, which is based on the position and distribution of separate units in texts, but does not give much attention to full lexical and grammatical meanings of these units. However, the evolution of cognitive, communicative and discursive aspects in language denotes inefficiency of classical approaches towards PoS theory, in particular referring to correlation between open and closed classes. Bearing it in mind and trying to validate our hypothesis we selected 94 lexical units, which conventionally are treated as one-word prepositions. On the basis of the BNC, 94 modern one-word prepositions were shortlisted to 49 lexical units. It was possible as the rest 45 words either were "pure/genuine" prepositions, which did not overlap any PoS or overlapped other word classes, but prepositions, what is not a research subject. As the type of relations, represented by lexical units, may differ a lot we decided to generalise the list and narrow it down only to those units, which bear temporal and locative characteristics, see Table 1. Thus, the final list comprises 39 lexical units, which have temporal and locative semes and can be without distinction defined both as adverbs and prepositions.

The present paper is a corpus-based research, centred on various types of complements which are used in the postposition to the lexical units under study. Quantitative data in Table 1 are to testify reasonableness of the above-mentioned assumptions and hypothesis.

Table 1 is divided into 2 equal parts - the former provides data, concerning lexical items (see column "Lexical items") described as prepositions; the latter - as adverbs. In the columns "Total quantity" and "Quantity per mln" one can find overall number and correlation of lexical items, used as prepositions or adverbs. In the columns "Noun Phrase (NP) complement" and "Alternative (Alt) complement" we can see total amount of complements used in the postposition to any lexical item.

Table 1 provides data and results of the corpus-based research of complements, which are used in the postposition to 39 lexical units under study. Conducting the research we believe it as reasonable to single out two main groups of complements, i.e. NP complements and Alternative complements. To distinguish between them, let us state that according to traditional grammar, prepositions, as opposed to adverbs, always govern "nominal complements or noun phrases, represented by a noun, pronoun or their syntactic equivalent, a nominal clause or an -ing clause, with the exception of that-clause and infinitive clause" (Klégr, 1997, p. 52), thus more exactly NPs heads or pre-modifiers are nouns, pronouns, determiners (articles etc.) and modifiers (adjectives etc.). Classical combinations of prepositions and NP Complements are:

1) On March 27, in Alexandra township outside Johannesburg, at least 14 people were killed when men armed with automatic weapons opened fire on mourners at a night-time vigil (BNC);

Example 1 provides the combination of Prep (outside) and Noun (Johannesburg);

2) Then when you swing hard at his foot, he lifts it so that your sweep passes underneath it (BNC);

In sentence 2 we observe the junction of Prep (underneath) + Pron (it);

3) Taunton, Somerset's county town, was founded during the time of King Ine, astride the peaceful, picturesque River Tone (BNC);

In sentence 3 Prep (astride) governs Det (the); 
(BNC)

4) Extracts from The Times grouped round major themes: Employment, Finance, Trade and Science

In example 4 Prep (round) is used together with Adj (major).

Table 1

Adverb-Preposition Overlapping in PDE

\begin{tabular}{|c|c|c|c|c|c|c|c|c|c|c|c|c|c|}
\hline \multirow[t]{3}{*}{ № } & \multirow{3}{*}{$\begin{array}{l}\text { Lexical } \\
\text { Item }\end{array}$} & \multicolumn{6}{|c|}{$\begin{array}{l}\text { PREPOSITION } \\
\end{array}$} & \multicolumn{6}{|c|}{ ADVERB } \\
\hline & & \multirow[t]{2}{*}{$\begin{array}{c}\text { Total } \\
\text { quantity }\end{array}$} & \multirow[t]{2}{*}{$\begin{array}{l}\text { Quantity } \\
\text { per mln }\end{array}$} & \multicolumn{2}{|c|}{$\begin{array}{c}N P \\
\text { Comp }\end{array}$} & \multicolumn{2}{|c|}{$\begin{array}{c}\text { Alt } \\
\text { Comp }\end{array}$} & \multirow[t]{2}{*}{$\begin{array}{c}\text { Total } \\
\text { quantity }\end{array}$} & \multirow[t]{2}{*}{$\begin{array}{l}\text { Quantity } \\
\text { per mln }\end{array}$} & \multicolumn{2}{|c|}{$\begin{array}{c}N P \\
\text { Comp }\end{array}$} & \multicolumn{2}{|c|}{$\begin{array}{c}\text { Alt } \\
\text { Comp }\end{array}$} \\
\hline & & & & Units & $\%$ & Units & $\%$ & & & Units & $\%$ & Units & $\%$ \\
\hline 1 & Aboard & 563 & 5.73 & 553 & 98.2 & 10 & 1.8 & 383 & 3.9 & 9 & 2.3 & 374 & 97.7 \\
\hline 2 & About & 146934 & 1494.55 & 124549 & 84.7 & 22385 & 15.3 & 44769 & 455.37 & 29050 & 64.9 & 15719 & 35.1 \\
\hline 3 & Above & 13165 & 133.91 & 12951 & 98.3 & 214 & 1.7 & 9207 & 93.65 & 336 & 3.7 & 8871 & 96.3 \\
\hline 4 & Across & 20635 & 209.89 & 19818 & 96.0 & 817 & 4.0 & 3340 & 33.97 & 44 & 1.3 & 3296 & 98.7 \\
\hline 5 & After & 90000 & 915.44 & 73556 & 81.7 & 16444 & 18.3 & 936 & 9.52 & 201 & 21.5 & 735 & 78.5 \\
\hline 6 & Along & 11796 & 119.98 & 11618 & 98.5 & 178 & 1.5 & 11647 & 118.47 & 1311 & 11.3 & 10336 & 88.7 \\
\hline 7 & Alongside & 2840 & 28.89 & 2800 & 98.6 & 40 & 1.4 & 363 & 3.69 & 44 & 12.1 & 319 & 87.9 \\
\hline 8 & Around & 22594 & 229.82 & 21961 & 97.2 & 633 & 2.8 & 20725 & 210.81 & 8940 & 43.2 & 11785 & 56.8 \\
\hline 9 & Astride & 115 & 1.17 & 115 & 100 & --- & 0 & 23 & 0.23 & 7 & 30.5 & 16 & 69.5 \\
\hline 10 & At & 521623 & 5305.71 & 469194 & 89.9 & 52429 & 10.1 & 28 & 0.28 & --- & 0 & 28 & 100 \\
\hline 11 & Before & 42148 & 428.71 & 27609 & 65.5 & 14539 & 34.5 & 13618 & 138.52 & 609 & 4.5 & 13009 & 95.5 \\
\hline 12 & Behind & 19056 & 193.83 & 18578 & 97.5 & 478 & 2.5 & 3274 & 33.3 & 63 & 2.0 & 3211 & 98.0 \\
\hline 13 & Below & 5376 & 54.68 & 5219 & 97.0 & 157 & 3.0 & 8655 & 88.03 & 1372 & 15.9 & 7283 & 84.1 \\
\hline 14 & Beneath & 4400 & 44.75 & 4365 & 99.2 & 35 & 0.8 & 368 & 3.74 & 10 & 2.7 & 358 & 97.3 \\
\hline 15 & Beside & 5358 & 54.5 & 5304 & 98.9 & 54 & 1.1 & 14 & 0.14 & 1 & 7.2 & 13 & 92.8 \\
\hline 16 & Between & 90191 & 917.38 & 85851 & 95.2 & 4340 & 4.8 & 306 & 3.11 & 9 & 3.0 & 297 & 97.0 \\
\hline 17 & Beyond & 10119 & 102.93 & 9759 & 96.4 & 360 & 3.6 & 1179 & 11.99 & 32 & 2.7 & 1147 & 97.3 \\
\hline 18 & By & 508658 & 5173.84 & 440444 & 86.6 & 68214 & 13.4 & 3522 & 35.82 & 89 & 2.5 & 3433 & 97.5 \\
\hline 19 & Down & 9253 & 94.12 & 8778 & 94.8 & 475 & 5.2 & 81125 & 825.17 & 18304 & 22.6 & 62821 & 77.4 \\
\hline 20 & Following & 1142 & 11.62 & 1124 & 98.4 & 18 & 1.6 & 445 & 4.53 & 359 & 80.7 & 86 & 19.3 \\
\hline 21 & For & 865253 & 8800.96 & 792328 & 91.6 & 72925 & 8.4 & 41 & 0.43 & 2 & 4.9 & 39 & 95.1 \\
\hline 22 & From & 424945 & 4322.35 & 379358 & 89.2 & 45587 & 10.8 & 3 & 0.03 & --- & 0 & 3 & 100 \\
\hline 23 & In & 1877602 & 19098.12 & 1831336 & 97.5 & 46266 & 2.5 & 56211 & 571.75 & 5256 & 9.4 & 50955 & 90.6 \\
\hline 24 & Inside & 7030 & 71.51 & 6923 & 98.5 & 107 & 1.5 & 4835 & 49.18 & 581 & 12.1 & 4254 & 87.9 \\
\hline 25 & Near & 13887 & 141.25 & 13621 & 98.1 & 266 & 1.9 & 2202 & 22.4 & 483 & 22.0 & 1719 & 78.0 \\
\hline 26 & Off & 20563 & 209.16 & 19821 & 96.4 & 742 & 3.6 & 46998 & 478.04 & 9969 & 21.2 & 37029 & 78.8 \\
\hline 27 & On & 642664 & 6536.89 & 616066 & 95.8 & 26598 & 4.2 & 86714 & 882.02 & 10108 & 11.7 & 76606 & 88.3 \\
\hline 28 & Opposite & 1091 & 11.1 & 1085 & 99.5 & 6 & 0.5 & 660 & 6.71 & 50 & 7.6 & 610 & 92.4 \\
\hline 29 & Outside & 11921 & 121.26 & 11026 & 92.5 & 895 & 7.5 & 5027 & 51.13 & 607 & 12.1 & 4420 & 87.9 \\
\hline 30 & Over & 73796 & 750.62 & 69413 & 94.1 & 4383 & 5.9 & 55962 & 569.22 & 30135 & 53.9 & 25827 & 46.1 \\
\hline 31 & Past & 6262 & 63.69 & 6079 & 97.1 & 183 & 2.9 & 2010 & 20.44 & 188 & 9.4 & 1822 & 90.6 \\
\hline 32 & Round & 11011 & 112.0 & 10749 & 97.6 & 262 & 2.4 & 13214 & 134.41 & 1561 & 11.8 & 11653 & 88.2 \\
\hline 33 & Since & 17475 & 177.75 & 14312 & 81.9 & 3163 & 18.1 & 2803 & 28.51 & 81 & 2.9 & 2722 & 97.1 \\
\hline 34 & Through & 71704 & 729.34 & 68298 & 95.2 & 3406 & 4.8 & 9149 & 93.06 & 245 & 2.7 & 8904 & 97.3 \\
\hline 35 & Throughout & 11438 & 116.34 & 11312 & 98.9 & 126 & 1.1 & 804 & 8.18 & 25 & 3.1 & 779 & 96.9 \\
\hline 36 & Under & 55022 & 559.66 & 53349 & 96.9 & 1673 & 3.1 & 5482 & 55.76 & 4589 & 83.7 & 893 & 16.3 \\
\hline 37 & Underneath & 970 & 9.87 & 930 & 95.8 & 40 & 4.2 & 813 & 8.27 & 129 & 15.9 & 684 & 84.1 \\
\hline 38 & $\mathrm{Up}$ & 7909 & 80.45 & 6874 & 86.9 & 1035 & 13.1 & 199216 & 2026.34 & 55471 & 27.9 & $\begin{array}{c}14374 \\
5\end{array}$ & 72.1 \\
\hline 39 & Within & 44268 & 450.27 & 43597 & 98.5 & 671 & 1.5 & 1277 & 12.99 & 25 & 2.0 & 1252 & 98.0 \\
\hline
\end{tabular}

On the contrary, Alternative Complements are represented by other parts of speech like verbs, adverbs, conjunctions and prepositions, which in accordance with classic grammar and PoS theory cannot be governed by prepositions. Quite a significant place is occupied by certain kind of punctuation used immediately after a preposition, as it is a sign of applying various clauses, which in fact are not governed by prepositions as well. However, adverbs "modify verbs, clauses, adjectives and other adverbs" (Downing, 2006, p. 503).

5) How far behind are the galleries and critics? (BNC);

In sentence 5 the author combines Adv (behind) and Verb (are);

6) They steadfastly refused to come anywhere near close enough (BNC);

In example $6 \boldsymbol{A d v}$ (near) is used with Adj (close);

7) He had not expected to run across Tubby Walters again, not within only two years of their end-ofwar farewells in London, and certainly not in Ireland (BNC);

Sentence 7 show the example of Adv (within) and Adv (only) combination;

8) DTS claims the Accommodator system, as well as handling telephone traffic and the facilities mentioned above, makes an important contribution to housekeeping, maintenance and billing functions (BNC).

In example 8 we observe the sample of a clause, where Adv (above) is followed by Pun (,). 
Therefore, such correlation between lexical units and their complements forms the grounds for the analysis and the results are represented in Table 1.

To organise and investigate the obtained results we employed basic elements of comparative-parametric method of linguistic research, developed by (Sternina, 2015, p. 92), (Pankratova, 2015, p. 9) and others. Pursuing intralingual research within the frame of the comparative-parametric method, Sternina (2013) developed a special grading rank for the rate of the phenomena under analysis (p. 208).

According to it, if the index weight equals 0 - it testifies the absence of the phenomenon;

from 0 to $9.99 \%$ - low degree;

from $10 \%$ to $29.99 \%$-noticeable degree;

from $30 \%$ to $49.99 \%$ - vivid degree;

from $50 \%$ to $69.99 \%$ - considerable degree;

from $70 \%$ to $89.99 \%$ - high degree;

from $90 \%$ to $99.9 \%$ - hyperhigh degree;

$100 \%$ index weight means absolute quantitative rate.

This grading rank is used for the subsequent research to figure out the quantitative rate of every lexical unit under study, whether their correlation with different types of complements conforms to their traditional grammar definition. It is rather necessary as almost every lexical unit in Table 1 is defined either as a preposition or as an adverb and can govern each type of a complement to various extents. We employed this scheme as believe it to be quite relevant for comparing units on the basis of the identical characteristics and its numbers are seen as plausible ones.

The first conclusion to be made on the basis of Table 1 is that most lexical units under study are traditionally registered in dictionaries and grammars as prepositions, but not adverbs - only 5 units from the total number of 39 units display higher frequency of use as adverbs than prepositions, namely: up (96.2 / 3.8), down (89.7 / 10.3), off (69.5 / 30.5), below (61.7 / 38.3), round (54.6 / 45.4).

2 lexical units - around (52.1 / 47.9), along (50.3 / 49.7) show almost the same key figures, a bit higher for prepositions.

Other 32 lexical units are more frequently used as prepositions than adverbs - the range is from $\mathbf{5 4 . 4 \%}$ as to underneath and up to $\mathbf{9 9 . 9 9 \%}$ as to at, for, from.

In the process of investigating the referred units, we assume the following: such lexical units as $\boldsymbol{u p}$, down, off, round, around, along initially denote motion or direction from one point to another (end) and thus another point is usually omitted if there is no need to specify it. For instance:

9) $5.45 \mathrm{pm}$ - They finally turn up (BNC);

In sentence 9 the place where people appeared is clear from the discourse and there is no need to repeat it;

10) The Shah was equal to these demolitions: 'If we pulled one down, he set up three' (BNC);

In sentence 10 "pull down" refers to the monuments again there is no sense to use "ground";

11) $4.00 \mathrm{pm}$ - We set off again; this time via Tony's home to collect a variety of possessions, finally arriving at hospital no.3 (BNC);

The idea of the travelling is already known, thus there is no specification after "off" in example 11;

12) She chases him round and round (BNC);

In example 12 "round and round" in fact means direction of movement, described in the previous sentence;

13) And I was scouting around vaguely aware that, in fact, I'd actually located it (BNC);

The idea of "around" from sentence 13 is explained earlier in the discourse; (BNC);

14) Don't go along in a dirty $T$ shirt and floppy gym shoes or try to over-impress or be antagonistic

Again there is no need to specify "along" in the sentence as it has an abstract meaning in sentence 14 .

These lexical units take Alternative Complements as there is no need to specify the place or direction, but it is necessary just to name it, generalize it.

Nevertheless, when such a need occurs, these words are traditionally described as prepositions, since they govern the point of specification. In case with other units from the list they either don't have a clear local or temporal point of reference or are characterised by quite a wide range of semantics, which requires specification within a word combination, sentence or discourse. For instance:

15) I would follow the police officers escorting the prisoner or prisoners $\underline{u p}$ a flight of stairs into the small but impressive court-room ... (BNC);

In sentence 15 "a flight of stairs" is used by the author just for the stylistic value and specification, as even without it the direction of movement could be decoded;

16) Dog at his heels as he went off $\underline{\text { down }}$ the road (BNC); 
In example 16 "down the road" is used to emphasise that a person leaves in the opposite direction, away from the speaker;

17) One day I would write it - and them - off the face of the earth (BNC);

"The face of the earth" in sentence 17 is a stylistic figure used for emphasis; likewise it could be substituted by "my mind" without any grammatical or semantic changes;

18) Round the corner was Dixon's Blazes, a blast furnace, and the Workers' Circle, where dreams of socialist emancipation were debated ... (BNC);

Specification in sentence 18 is necessary as the unit "round" is characterised by a wide range of semantics and must be specified either in the sentence or in the discourse;

19) By working co-operatively, long-term, with the people around me, I hope to continue for some time yet (BNC);

In sentence 19 specificator " $m e$ " is used to limit the number of people the speaker is talking about, as if used without it, the sentence would mean "people around the speaker at the moment";

20) Between these two ridges the fire of the sunset falls along the trough of the sea, dyeing it with an awful but glorious light ... (BNC).

In example 20 the author deliberately underlines the place, where the fire of the sunset falls.

Therefore, in every sentence the authors for the sake of discourse completeness and coherence and to transfer the idea use complements, which disclose authors' intensions.

Speaking of the unit below, which usually does not govern NP Complement, we believe that the explanation lies in the original structure of below - a combination of be (Prep) + low (Adj/Noun) and its semantics, as "low" initially meant "Situated not far above the ground or some other downward limit; not elevated in position", while "be" was a preposition of place "on, at, near etc." (Hall \& Meritt, 2008).

Due to this explanation below always defines a distinct point of location of an object, i.e. under the point of reference and there is no need to specify it additionally, see example 21 . If another local point is used in a complement, see example 22, it means that additional specification is required.

21) From my place on the gallery I could keep a watch on Claire's door and on what was happening in the hall below (BNC);

In sentence 21 "below" distinctly represents the position of the object "under foot", and does not require any other additional references;

22) In this, as in Western perspective, the horizon line is somewhere below the middle of the picture (BNC).

In sentence 22 historical meaning of "below" is modified and requires clarifications, without which the recipient may understand that the horizon line is "not below the middle of the picture", but just "not far above the ground".

"Below" is an obvious indicative and illustration of semantic substitution and transposition, when one and the same word in diachronic perspective started acquiring other semantic components without any structural changes. However, it is not the case of "below" only, other lexical units under study either consist of two or more components, the semantics of which should be taken into consideration, or are one-word units, initial semantics of which might undergo transformations.

Thus, we may conclude that in most cases functional transposition has been occurring, in diachronic perspective, from a closed word class (prepositions) to an open word class (adverbs), see (Kovbasko, 2015). Further diachronic research of this phenomenon may be of great significance and interest as it can support or refute our leading hypothesis that lexical units under study initially are prepositions, which in their majority have been formed due to grammaticalization and in the course of time due to functional transposition started to function as adverbs.

Another assumption to be made on the basis of Table 1 is that according to the comparative-parametric method only 1 word -astride - is characterised by an absolute quantitative rate; however 30 lexical units are designated as hyperhigh units; 7 words - are typified by a high degree; while 1 word - before - is characterised as a unit with a considerable degree. It means that in the majority of cases the lexical units under study function as prepositions, governing NP Complements (94.2\% of the total amount) and in rare cases - Alternative Complements $(5.8 \%$ of the total amount) - i.e. the combination: Prep + NP Complement is characterised by a hyperhigh degree of quantitative rate. Let's analyse the outermost cases.

Astride, being at first glance a semantically limited word as it means "with the legs stretched wide apart, or so that one leg is on each side of some object between", has evolved a wide range of figurative meanings, especially when someone speaks of geographical places and other objects and implies "to extend/spread out", and thus it needs that "geographical" or any other specification, see example 23: 
23) Arlington Mill, in this picturesque Cotswold village astride the River Coln, has been both a corn and fulling mill in its time (BNC).

Before, being both a locative and temporal lexical unit, does not require direct specification as very often the place/time can be constructed from discourse, where these events are usually described.

24) It has all happened before, he wrote, and it will all happen again (BNC).

If analysing the use of lexical units as adverbs governing Alternative Complements, see Table 1, it is possible to state that according to the comparative-parametric method only 2 words - at, from - are determined as those of absolute quantitative rate, 18 words belong to the group of hyperhigh units; 13 words are characterised by high degree; 2 words - around, astride - belong to a group with a considerable rate; 2 words - over, about - are determined by a vivid degree; 2 words - following, under - have a noticeable degree. These results show that there is no such unanimity as to the use of complements among the lexical units defined as adverbs, and the combination Adv + Alternative Complement is actual in $\mathbf{8 3 . 4 \%}$ of examples (high degree), while NP Complements are used in $16.6 \%$ (noticeable degree).

Despite the fact that $\boldsymbol{a t}$ and from are characterised by an absolute quantitative rate their total number in the language is unrepresentative - 28 and 3 units respectively. Thus, we suppose it would make more sense to analyse other subsequent lexical units - across, within. Both words imply direction and location correspondingly, see examples 25 and 26 however this information can be specified by authors, in case of necessity:

25) I went across and grabbed her by the lapels (BNC);

In example 25 the meaning of across is disclosed in the previous sentence;

26) Amnesty's job is to breach these walls, to discover the truth within, and then to act (BNC);

In example 26 the meaning of within can be decoded from the previous words in the sentence.

These data testify that the lexical units under analysis often govern NP Complements in comparison with Alternative Complements. This proves the hypothesis that functional-grammatical transposition has been occurring within the word class of prepositions.

\section{Conclusions}

The corpus-based approach to local and temporal prepositions and adverbs overlapping in PDE refutes general bias in interpreting prepositions as lexical units, which necessarily govern NP Complements, while adverbs fail to do this.

We assume that POS division in PDE should be based not on synchronic syntactic rules and principles of word correlation, but on diachronic analysis in general and analysis of lexical units in Old English and Middle English periods. This is because the main syntactic and semantic changes have been taken place throughout the process of their evolvement, and nowadays researchers just acknowledge them not even bothering to get to the root of the phenomena either literally or metaphorically. Thus, current prepositionadverb overlapping is the result of functional-grammatical transposition, which has been occurring over the language development in terms of "preposition $\rightarrow$ adverb" line, what is proved by the undertaken diachronic analysis and PDE corpus-based research; yet nevertheless further OE analyses are eligible and potential.

\section{References:}

British National Corpus (2016)Rtrieved from http://www.natcorp.ox.ac.uk/

Downing, A., \& Locke, Ph. (2006) English Grammar: a University Course. London and New York: Routledge.

Essberger, J. (2009). English Prepositions List. Cambridge: CUP.

Hall, J. R., \& Meritt, H. D. (2008). A Concise Anglo-Saxon Dictionary. Cambridge: CUP.

Heaton J. B. (1966) Prepositions and Adverbial Particles. London: Longmans, Green \& Co Ltd.

Ketel, E. E. (1991). The Historiography of Grammatical Concepts: 19th and 20th-century Changes in the Subject-Predicate Conception and the Problem of their Historical Reconstruction. Amsterdam, Atlanta, GA: Rodopi.

Kiefer, F. (2009). Types of Adverbials and the Fine Structures of Events. Berlin, N.Y.: Mouton de Gruyter. https://doi.org/10.1515/9783110214802.2.247

Kiss, K. E. (2009). Syntactic, Semantic, and Prosodic Factors Determining the Position of Adverbial Adjuncts. Berlin, N.Y.: Mouton de Gruyter. https://doi.org/10.1515/9783110214802.1.21

Klégr, A. (1997). English Complex Prepositions of the Prepositional Phrase Type (Philologia 5. Prague Studies in English XXII). Praha: Acta Universitatis Carolinae.

Oxford English Dictionary (2009). Oxford: OUP.

Urogdi, B. (2009). Temporal Adverbial Clauses with or without Operator Movement. Berlin, N.Y.: Mouton de Gruyter. https://doi.org/10.1515/9783110214802.1.133

Kovbasko, Yu. H. (2015). Hramatykalizatsiia yak peredumova dlia funktsionalno-hramatychnoi transpozytsii [Grammaticalization as precondition for functional and grammatical transposition]. Naukovi zapysky Natsionalnoho Universytetu "Ostrozka Akademiia": Seriia "Filolohichna", 55, 118-121.

Lekant, P. A. (2007) Grammaticheskie kategorii slova i predlozhenija [Grammatical categories of a word and sentence]. Moscow, Russia: MGOU. 
Pankratova, M. E. (2015) Semantika narechnogo slova v sovremennom anglijskom jazyke [Semantics of adverbial words in contemporary English]. Extended abstract of candidate's thesis. Voronezh, Russia.

Sternina, M. A. (2013). O vozmozhnostjah ispol'zovanija sopostavitel'no-parametricheskogo metoda dlja vnutrijazykovyh issledovanij [On the possibilities of usage the comparative-parametric method for the intralingual research]. Izvestija VGPU: "Gumanitarnye nauki", 2 (261), 207-209.

Sternina, M. A. (2015). Sopostavitel'no-parametricheskij metod lingvisticheskih issledovanij: pervye itogi [Comparative-parametric method of linguistic research: first results]. Vestnik VGPU: "Filologija. Zhurnalistika", 2 (261), 92-94.

Received: September 21, 2016

Accepted: November 22, 2016 